Article

\title{
X-ray Photospectroscopy and Electronic Studies of Reactor Parameters on Photocatalytic Hydrogenation of Carbon Dioxide by Defect-Laden Indium Oxide Hydroxide Nanorods
}

\author{
Joel Y. Y. Loh ${ }^{1}$ (1) and Nazir P. Kherani ${ }^{1,2, *}$ \\ 1 Department of Electrical and Computing Engineering, University of Toronto, Toronto, ON M5S 3G4, Canada; \\ joel.loh@mail.utoronto.ca \\ 2 Department of Material Science and Engineering, University of Toronto, Toronto, ON M5S 3E4, Canada \\ * Correspondence: kherani@ecf.utoronto.ca; Tel.: +1-416-946-7372
}

Academic Editors: Marcelo I. Guzman and German Mills

Received: 31 August 2019; Accepted: 9 October 2019; Published: 23 October 2019

check for updates

\begin{abstract}
In the study reported herein, glovebox-protected X-ray photoelectron spectroscopy (XPS) and in situ Hall charge carrier measurements provide new insights into the surface physical chemistry of gaseous $\mathrm{H}_{2}, \mathrm{CO}_{2}$, and $\mathrm{H}_{2}+\mathrm{CO}_{2}$ combined with nanostructured $\operatorname{In}_{2} \mathrm{O}_{(3-x)}(\mathrm{OH})_{y}$ nanorods, which ensue under photochemical and thermochemical operating conditions. Heterolytic dissociation of $\mathrm{H}_{2}$ in $\mathrm{H}_{2}$-only atmosphere appears to occur mainly under dark and ambient temperature conditions, while the greatest amount of $\mathrm{OH}$ shoulder expansion in $\mathrm{H}_{2}+\mathrm{CO}_{2}$ atmosphere appears to mainly occur under photoilluminated conditions. These results correlate with those of the Hall measurements, which show that the prevalence of homolytic over heterolytic dissociation at increasing temperatures leads to a steeper rate of increase in carrier concentrations; and that $\mathrm{H}_{2}$ adsorption is more prevalent than $\mathrm{CO}_{2}$ in $\mathrm{H}_{2}+\mathrm{CO}_{2}$ photoillumination conditions.
\end{abstract}

Keywords: indium oxide; reverse water gas shift; X-ray photospectroscopy; hall mobility

\section{Introduction}

Photocatalysts are useful tools in the reduction of $\mathrm{CO}_{2}$ under solar radiation to generate sustainable fuels [1-3]. The thermal dehydroxylation of $\operatorname{In}(\mathrm{OH})_{3}$ at $50{ }^{\circ} \mathrm{C}$ yields the cubic bixbyite $\operatorname{In}_{2} \mathrm{O}_{3}$ polymorph, the crystal structure of which is based on fluorite, with $25 \%$ of the oxide ions missing from the lattice. By controlling the thermal profile used for the dehydroxylation of the $\operatorname{In}(\mathrm{OH})_{3}$ precursor, a partially dehydroxylated indium oxide hydroxide is obtained, in which the bixbyite structure is retained [4-8]. By quantifying the amount of water eliminated from the lattice of $\operatorname{In}(\mathrm{OH})_{3}$ by thermal gravimetric analysis, the stoichiometry of the oxide and hydroxide groups in the obtained material can be established according to the balanced reaction equation, with the following intermediate stochiometric composition: $2 \mathrm{In}(\mathrm{OH})_{3} \rightarrow \mathrm{In}_{2} \mathrm{O}_{2 x}(\mathrm{OH})_{(6-x)}+2 \times \mathrm{H}_{2} \mathrm{O} \rightarrow \mathrm{In}_{2} \mathrm{O}_{3}+3 \mathrm{H}_{2} \mathrm{O}\left(\sim 30{ }^{\circ} \mathrm{C}\right)$. The intermediate indium oxide hydroxide product at $250{ }^{\circ} \mathrm{C} \operatorname{In}_{2} \mathrm{O}_{2 x}(\mathrm{OH})_{(6-4 x)}$, denoted $\operatorname{In}_{2} \mathrm{O}_{(3-x)}(\mathrm{OH})_{y}$, thus, contains hydroxide

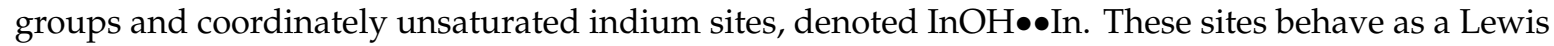
base and a Lewis acid individually, but when coupled together can be viewed as a metastable surface frustrated Lewis pair (SFLP) site $[9,10]$. Oxygen vacancies also exist in the lattice of $\operatorname{In}_{2} \mathrm{O}_{(3-x)}(\mathrm{OH})_{y}$, which serve to increase the Lewis acidity of adjacent indium sites. These defects, both coupled and uncoupled, all play pivotal roles in catalyzing the light-assisted reverse water gas shift (RWGS) reaction [11]: $\mathrm{CO}_{2}+\mathrm{H}_{2} \rightarrow \mathrm{CO}+\mathrm{H}_{2} \mathrm{O}$. Depending on the ratio of $\mathrm{H}_{2}$ to $\mathrm{CO}_{2}$ pressure fraction, the selectivity of the RWGS can range from $\mathrm{CH}_{4}$ to $\mathrm{CO}$ or $\mathrm{CH}_{3} \mathrm{OH}$. The main product of the 1:1 pressure 
ratio of $\mathrm{H}_{2}: \mathrm{CO}_{2}$ on the $\mathrm{In}_{2} \mathrm{O}_{(3-\mathrm{x})}(\mathrm{OH})_{\mathrm{y}}$ catalyst is $\mathrm{CO}$, with a typical yield range of $20-120 \mathrm{ppm} / \mathrm{g}$.cat over a reactor temperature of $100-200{ }^{\circ} \mathrm{C}$, with minor $\mathrm{CH}_{4}$ yield.

For amplification, the first step in the RWGS catalytic cycle $\left(\mathrm{CO}_{2}+\mathrm{H}_{2} \rightarrow \mathrm{CO}+\mathrm{H}_{2} \mathrm{O}\right)$ is purported to involve heterolysis of $\mathrm{H}_{2}$ on the SFLP to form $\mathrm{InOH}_{2} \bullet \bullet \mathrm{InH}$, comprised of a proton bound to the hydroxide Lewis base site and a negatively charged hydride to the coordinately unsaturated Lewis acid indium site. The rationale for the heterolytic splitting of $\mathrm{H}_{2}$ is due to the strong charge polarization effect of the indium site and $\mathrm{OH}$ site [12-14]. In general, various polar metal oxides, such as $\mathrm{MgO}$ and $\mathrm{CeO}_{2}$ [15-17] were shown to have strong polarization between the metal and oxide sites, which would heterolytically split $\mathrm{H}_{2}$; in $\operatorname{In}_{2} \mathrm{O}_{(3-\mathrm{x})}(\mathrm{OH})_{\mathrm{y}}$ the polarization is induced by the presence of the oxygen vacancy between the indium and $\mathrm{OH}$ sites. In the rest of the cycle, an intermediate formate carbonate species is generated on the $\mathrm{InOH}_{2} \bullet \bullet \mathrm{InH}$ supersite, before decomposing into $\mathrm{CO}$ and $\mathrm{H}_{2} \mathrm{O}$ from the $\mathrm{C}-\mathrm{OH}_{2} \mathrm{In}$ end and the $\mathrm{O}-\mathrm{HIn}$ end. In the work described herein, quasi-operando X-ray photoelectron spectroscopy (XPS) probes the interaction of $\mathrm{H}_{2}, \mathrm{CO}_{2}$, and $\mathrm{H}_{2}+\mathrm{CO}_{2}$ with the surface of pristine nanostructured $\operatorname{In}_{2} \mathrm{O}_{(3-\mathrm{x})}(\mathrm{OH})_{\mathrm{y}}$. The difference between an ex situ XPS measurement and the following study is that the reactors with the samples contained within were directly transferred into the glovebox after the various gas treatments, and the samples were transferred to the XPS within the argon-filled glovebox. Hence, the surface condition reflects that of the stable chemisorbed species after reactor treatments. These results provide a deeper understanding of the chemistry in the ground and excited states relevant to the RWGS reaction. We also conducted in situ Hall carrier property measurements under the various gas reactant atmospheres in dark and photoillumination conditions, which allowed us to associate the chemisorption of the reactants to the electronic properties of the $\mathrm{In}_{2} \mathrm{O}_{(3-\mathrm{x})}(\mathrm{OH})_{\mathrm{y}}$ nanorods.

\section{Results and Discussion}

The CO production rate from the reverse water gas shift reaction on $\operatorname{In}_{2} \mathrm{O}_{(3-\mathrm{x})}(\mathrm{OH})_{\mathrm{y}}$ nanorods shows a significantly greater enhancement under white light photoillumination of $140 \mathrm{~mW} / \mathrm{cm}^{2}$ than under dark conditions, with the increase in $\mathrm{CO}$ rate diminishing with higher temperatures. The maximum rate under white light and reactor temperature of $210^{\circ} \mathrm{C}$ is $50.2 \mu \mathrm{mol} / \mathrm{g}$.cat/hour, with a pseudo activation energy of $10.9 \mathrm{~kJ} / \mathrm{mol} / \mathrm{K}$, which is smaller by a factor of 0.46 than the activation energy under dark conditions. The XPS O1s core-level binding energies of $\operatorname{In}_{2} \mathrm{O}_{(3-\mathrm{x})}(\mathrm{OH})_{\mathrm{y}}$ nanorods in a vacuum can be resolved into four peaks (limited to a maximum of $1.4 \mathrm{eV} \mathrm{FWHM}$ ), assigned to lattice oxide around $\sim 529.5 \mathrm{eV}$, oxygen vacancy $\sim 530.5 \mathrm{eV}$, hydroxide $\sim 532 \mathrm{eV}$, and protonated $\mathrm{OH}$ groups at $\sim 532.5 \mathrm{eV}$ (Figure 1b). The line widths of these O1s peaks are often broad and asymmetric because of multiple site occupancies of oxide lattice $\mathrm{O}_{\text {lattice }}\left(40 \%\right.$ of total species), oxygen vacancies $\mathrm{O}_{\mathrm{vac}}(21 \%)$, and hydroxide $\mathrm{OH}$ type species $(39 \%)$ on the surface of $\operatorname{In}_{2} \mathrm{O}_{(3-\mathrm{x})}(\mathrm{OH})_{y}$. The effective positive charge of the proton bonded to the oxide site of the hydroxide causes the O1s ionization potentials to shift to higher energy than the lattice oxide, while the protonated $\mathrm{OH}$ species $\left(\mathrm{H}^{+} \mathrm{OH}\right)(14 \%$ of total species $)$ arising from ambient moisture during synthesis preparation $[18,19]$ causes a positive shift for some of the $\mathrm{OH}$ groups, which all result in a broad $\mathrm{OH}$ shoulder. In addition, the presence of an oxygen vacancy in the oxide coordination sphere of indium enhances binding of the remaining oxides to the indium, which is manifest as a shift to higher energy of the O1s ionization potentials. We note that all In3d peaks were normalized between the various conditions, and the same normalization factor applied towards the O1s and C1s spectra. The corresponding In3d XPS results for nanostructured $\mathrm{In}_{2} \mathrm{O}_{(3-\mathrm{x})} \mathrm{OH}_{\mathrm{y}}$ are shown in (Figure 1c). The In $3 \mathrm{~d}^{3 / 2}$ spin orbit component is found to have an ionization potential around $444 \mathrm{eV}$. Its line width contains contributions from In-OH and In-O species, of which the $41 \%$ ratio of $\mathrm{OH}$-type species over the total is similar to that of the O1s spectrum. 

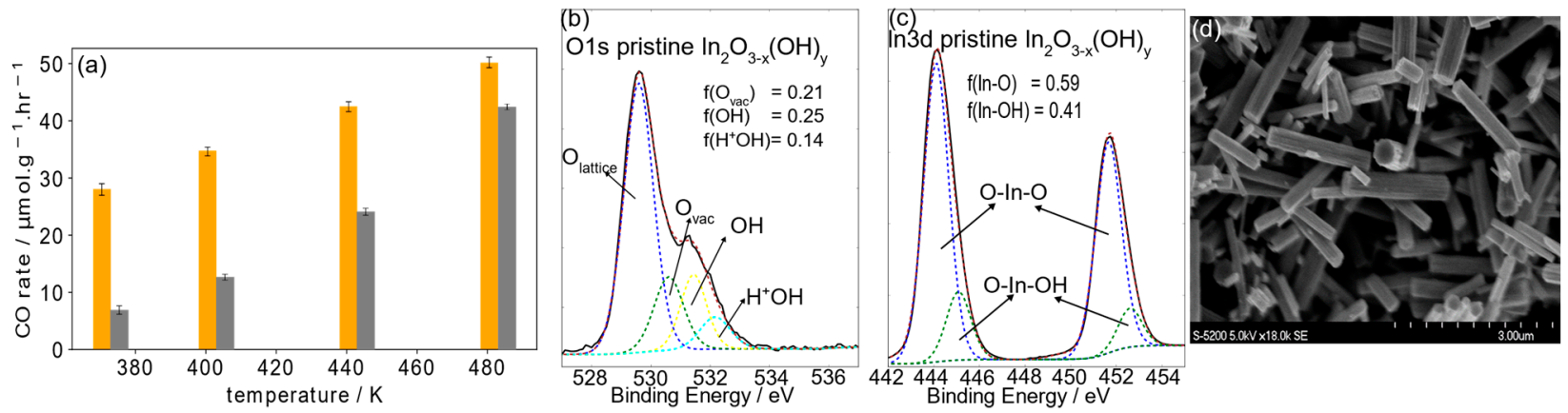

Figure 1. (a) The $\mathrm{CO}$ production rate with the $\operatorname{In}_{2} \mathrm{O}_{(3-\mathrm{x})}(\mathrm{OH}) \mathrm{y}$ catalyst under white light at 1:1 pressure ratio of $\mathrm{H}_{2}: \mathrm{CO}_{2}$ gas atmosphere, and under dark conditions with increasing reactor temperatures. $(\mathbf{b}, \mathbf{c})$ The O1s and In3d XPS spectrum of $\operatorname{In}_{2} \mathrm{O}_{(3-\mathrm{x})}(\mathrm{OH})_{\mathrm{y}}$ nanorods as prepared. (d) SEM topographical image of $\operatorname{In}_{2} \mathrm{O}_{(3-x)}(\mathrm{OH})_{y}$ nanorods.

On exposure of $\operatorname{In}_{2} \mathrm{O}_{(3-x)}(\mathrm{OH})_{y}$ nanorods to $\mathrm{H}_{2}$ at under dark and ambient room temperature (dark ambient) conditions a dramatic increase in the intensity and shift to high energy of approximately $0.5 \mathrm{eV}$ occurs for the O1s binding energy of the hydroxide (Figure 2). This observation flags the dissociation of $\mathrm{H}_{2}$ on the surface of $\operatorname{In}_{2} \mathrm{O}_{(3-\mathrm{x})}(\mathrm{OH})_{\mathrm{y}}$. Noticeably, the fraction of $\mathrm{O}_{\mathrm{vac}}$ remains similar for all conditions under $\mathrm{H}_{2}$, indicating that the new hydroxide formation associated with $\sim 532.2 \mathrm{eV}$ is mostly hydrogen adatoms on lattice oxide sites to form bridging $\mathrm{OH}$ groups. Concomitantly the In $3 d^{3 / 2}$ peak undergoes a notable shift to lower energy implying the indium is experiencing a lower effective nuclear charge (Figure $2 b$ ). This behavior arises from a coordinately unsaturated Lewis acidic surface indium site bonded to a highly nucleophilic hydride formed by heterolysis of $\mathrm{H}_{2}$ on a SFLP site, which must dominate the opposing effect of protonation (Figure 2d). In addition, homolysis of $\mathrm{H}_{2}$ on hydroxide surface sites adjacent the oxygen vacancy sites, protonates these $\mathrm{OH}$ groups. The associated injection of charge-balancing electrons into defect indium sites cause the In $3 \mathrm{~d}^{3 / 2}$ peak to shift to lower energy, providing it overrides the countering effect of protonation. With $\mathrm{H}_{2}$ exposure under photoillumination, the intensity of the $\mathrm{OH}$ shoulder shrinks below its dark ambient value. Since the $\mathrm{OH}$ shoulder also experiences a small binding energy decrease from dark ambient to phototreatment, this indicates that $\mathrm{H}^{+}$adatoms on $\mathrm{OH}$ groups are removed, and less so for $\mathrm{H}^{+}$adatoms on lattice oxide sites. Heating at $150{ }^{\circ} \mathrm{C}$ causes further shrinkage of the intensity of this $\mathrm{OH}$ shoulder. The $\mathrm{OH}$ shoulder binding energy is similar to that of the $\mathrm{H}_{2}$ dark ambient condition, indicating that more $\mathrm{H}$ adatoms on lattice oxides are removed and less so for $\mathrm{H}$ adatoms bound on $\mathrm{OH}$ groups. These observations signal the photochemical and thermochemical induced loss of $\mathrm{H}_{2} \mathrm{O}$ from protonated hydroxide and indium hydride sites which indicates that indium hydride sites are photo and thermally unstable. Additionally, with introduction of $\mathrm{H}_{2}$ there is a diminishment of the intensity of $\mathrm{C} 1$ s peaks indicating removal of $\mathrm{C}-\mathrm{C}$ surface contaminants on the $\operatorname{In}_{2} \mathrm{O}_{(3-\mathrm{x})} \mathrm{OH}_{\mathrm{y}}$ nanorods (Figure 2e). Further information on the deconvolution of the O1s spectra are shown in the supplementary section. 

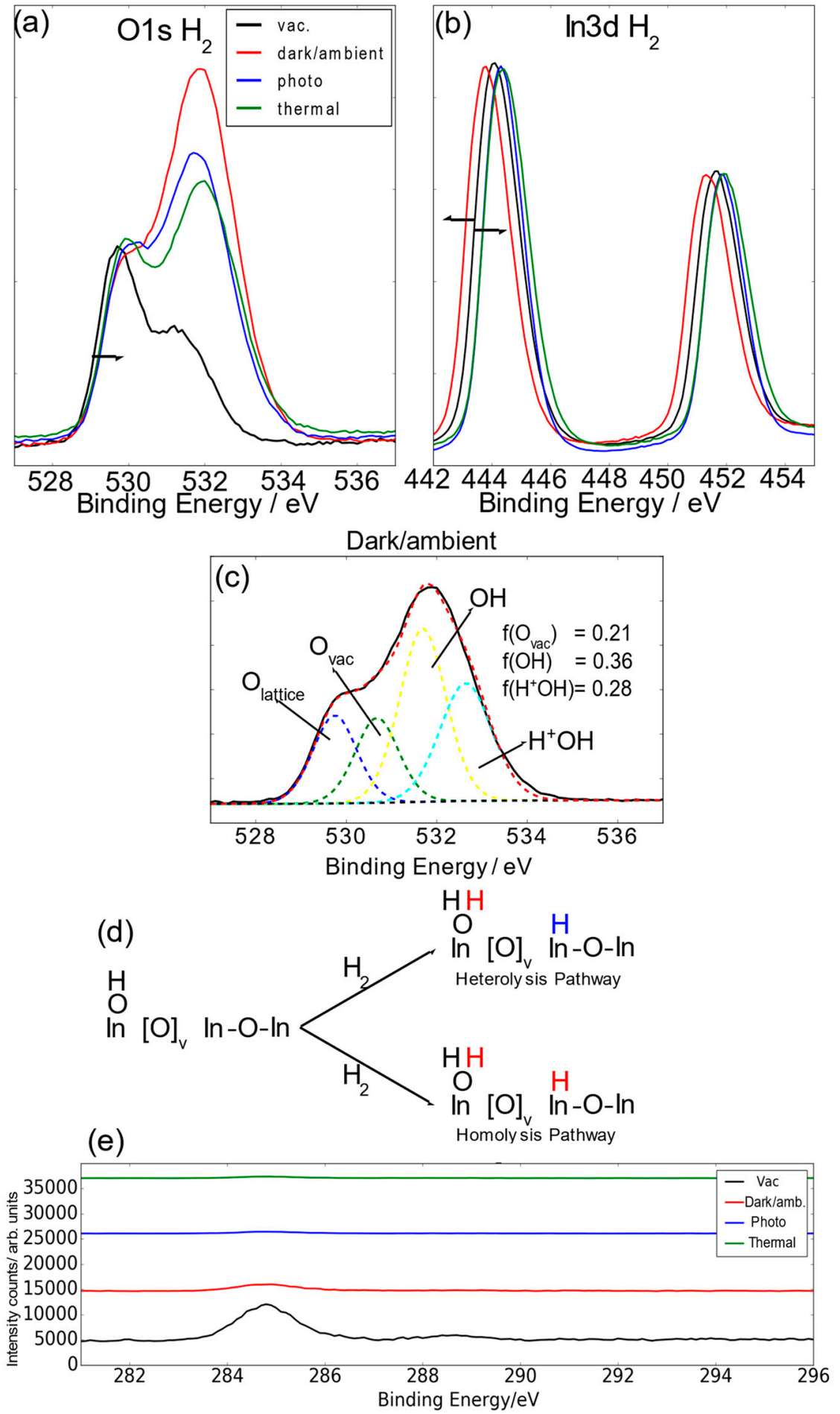

Figure 2. (a,b) The O1s and In3d X-ray photoelectron spectroscopy (XPS) spectra of $\operatorname{In}_{2} \mathrm{O}_{(3-\mathrm{x})}(\mathrm{OH})_{\mathrm{y}}$ nanorods in $\mathrm{H}_{2}$ under various reactor conditions in comparison with the pristine surface shown in Figure 1. (c) The XPS deconvolution of the O1s spectrum under $\mathrm{H}_{2}$ dark ambient conditions into various oxygen species. (d) Heterolysis and homolysis dissociation of $\mathrm{H}_{2}$ molecules over a surface frustrated Lewis acid-base pair site. (e) C1s spectra of $\operatorname{In}_{2} \mathrm{O}_{(3-x)}(\mathrm{OH})_{y}$ under $\mathrm{H}_{2}$ in various conditions.

The XPS study of O1s, In3d, and C1s surface species arising from the interaction of the acidic $\mathrm{CO}_{2}$ gas probe under dark ambient conditions on pristine, nanostructured $\operatorname{In}_{2} \mathrm{O}_{(3-x)}(\mathrm{OH})_{y}$ is rich in detail (Figure 3). In the C1s XPS, the growth of new peaks in the region of $285-288 \mathrm{eV}$ signals the adsorption or reaction of $\mathrm{CO}_{2}$ with oxygen vacancy, hydroxide, and coordinately unsaturated 
indium surface sites. Monodentate configurations are more favorable on surfaces with high basicity and bidentate, or tridentate configurations on surfaces with low basicity. It has been shown that on $\mathrm{In}_{2} \mathrm{O}_{3}$ surfaces, tridentate and bidentate configurations are favourable [12]. For example, two types of tridentate configurations are energetically favorable, where in one case, the carbonate bridges two In-O-In chains to form a cross-wise configuration with an absorption energy of $-1.14 \mathrm{eVm}$; in the other case, a tridentate configuration, where the $\mathrm{CO}_{2}$ is in the same plane as In-O-In, the absorption energy is $-1.25 \mathrm{eV}$. A conventional bidentate configuration of carbonate has an absorption energy of $-0.70 \mathrm{eV}$. The significant amount of $\mathrm{C}-\mathrm{O}$ and $\mathrm{O}=\mathrm{C}$ signals indicate that bidentate and tridentate carbonate configurations are dominant, while the increased $\mathrm{O}=\mathrm{C}-\mathrm{O} / \mathrm{O}=\mathrm{C}-\mathrm{OH}$ signal indicates bicarbonate products from $\mathrm{CO}_{2}$ reactions with $\mathrm{OH}$ groups. This model receives support from the corresponding O1s XPS, where adsorption or reaction of $\mathrm{CO}_{2}$ in general with $\mathrm{In}_{2} \mathrm{O}_{(3-x)} \mathrm{OH}_{y}$ increases the effective nuclear charge of the oxide, seen as a small shift of the O1s to higher energy. The hydroxide shoulder around $532 \mathrm{eV}$ increases in height and widens in dark ambient $\mathrm{CO}_{2}$ atmosphere, indicating highly positively charged oxide species as a result of the exposure of carbonate species to the O1s spectrum, with $\mathrm{C}-\mathrm{O}$ species in the range of $531.5-532.0 \mathrm{eV}, \mathrm{C}=\mathrm{O}$ in the range of $532.0-533.0 \mathrm{eV}$, and $\mathrm{O}=\mathrm{C}-\mathrm{O}$ species from 533.3-533.6 eV. The effect of light removes the higher binding energy component in the O1s spectrum, indicating surface bicarbonate fragmenting to $\mathrm{CO}_{2}$ and $\mathrm{H}_{2} \mathrm{O}$. The remaining bidentate and tridentate carbonates induce a higher $\mathrm{OH}$ shoulder than that of the vacuum state. The removal of bidentate carbonates to leave behind carbonate configurations with dominant $\mathrm{C}-\mathrm{O}$ bonds under thermal treatment narrows the $\mathrm{OH}$ shoulder and shifts the $\mathrm{O}_{\text {Lattice }}$ subpeak to a higher binding energy, which indicates that either tridentate carbonates or oxygen vacancies may have been filled by carbon dioxide to form species with $\mathrm{C}-\mathrm{O}$ bonds. This indicates that only such carbonate species persist under thermal treatment.

On exposure of nanostructured $\operatorname{In}_{2} \mathrm{O}_{(3-x)} \mathrm{OH}_{y}$ to both $\mathrm{H}_{2}$ and $\mathrm{CO}_{2}$ under ambient temperature, thermal, and photo conditions, the O1s XPS spectrum shows a substantial increase in the intensity of the hydroxide shoulder, with a concurrent shift to higher energy of the latter oxide peak, while the In $3 \mathrm{~d}$ XPS spectra show a similarly small shift. The C1s XPS spectra reveal the presence of C-O-containing species generated photochemically from the reaction of $\mathrm{H}_{2}$ and $\mathrm{CO}_{2}$ to generate a $\mathrm{C} 1 \mathrm{~s}$ spectra similar to that of $\mathrm{CO}_{2}$-only thermal conditions (Figure 4). There is also an increased C1s signal at $\sim 288-289 \mathrm{eV}$, indicating $\mathrm{C}=\mathrm{O}$ and $\mathrm{O}-\mathrm{C}=\mathrm{O}$ species. Since the $\mathrm{O} 1 \mathrm{~s}$ ionization potential shift is greater for photo than for dark ambient conditions, this implies that part of the $\mathrm{OH}$ shoulder height increase is due to increased $\mathrm{H}_{2}$ dissociation on both $\mathrm{OH}$ and $\mathrm{O}_{\text {Lattice }}$ sites, and part of it is due to increased carbonate formation. The results, thus, suggest that the surface is highly active under photo conditions. $\mathrm{H}_{2}+\mathrm{CO}_{2}$ mix to form a basic surface that enables adsorption of $\mathrm{CO}_{2}$ molecules as bidentate and tridentate species, since $\mathrm{C}-\mathrm{O}$ and $\mathrm{O}-\mathrm{C}=\mathrm{O}$ bonds seem to be the most stable bond formations under photo conditions. This can be linked to the photoexcited valence band holes and conduction band electrons into the hydroxide Lewis base defect near the conduction band edge, and indium Lewis acid defects near the valence band edge. The trapped electron and hole enhance the Lewis acidity and basicity of any indium hydride and protonated hydroxide group in the excited state, compared to the ground state [20,21]. However, one difference between the $\mathrm{H}_{2}$ and $\mathrm{H}_{2}+\mathrm{CO}_{2}$ atmosphere is the straddle between the $\mathrm{O}_{\text {lattice }}$ peak and $\mathrm{OH}$ species-type shoulder, where there is a deeper saddle for the $\mathrm{H}_{2}+\mathrm{CO}_{2}$ case but less so for the $\mathrm{H}_{2}$ only case, indicating a small $\mathrm{O}_{\mathrm{vac}}$ fraction decrease from $22 \%$ in the $\mathrm{H}_{2}$-only condition to $18 \%$ in $\mathrm{H}_{2}+\mathrm{CO}_{2}$ photoillumination. Taken together, it is clear that the presence of $\mathrm{OH}$ and $\mathrm{O}_{\mathrm{vac}}$ sites create a strong polarization effect in both homolytic and heterolytic dissociation of $\mathrm{H}_{2}$ to form hydride $\mathrm{H}^{-}$ adatoms on the neighboring indium sites, $\mathrm{H}^{+} \mathrm{OH}$ sites, and $\mathrm{H}^{+} \mathrm{O}$ sites. The $\mathrm{O} 1$ s spectra consistently shows a high $\mathrm{OH}$-type peak with an increased binding energy compared to vacuum conditions. $\mathrm{H}^{+} \mathrm{OH}$ and $\mathrm{H}^{+} \mathrm{O}$ sites, thus, persist mostly under photoillumination conditions due to stabilizing effects of the addition of photoexcited holes. In addition, there is also some indication that oxygen vacancies are filled in the $\mathrm{CO}_{2}$-only and $\mathrm{H}_{2}+\mathrm{CO}_{2}$ atmosphere. A possible reaction pathway involves carbonate filling of oxygen vacancies to form a bidentate-like carbonate with a $\mathrm{C}-\mathrm{O}$ bond, with an adsorption 
energy of $-0.61 \mathrm{eV}$. This is activated by a neighboring In-H hydride to form a formate species, with a small activation energy barrier of $0.15 \mathrm{eV}$ and an exothermic reaction energy of $-0.21 \mathrm{eV}$ [12].
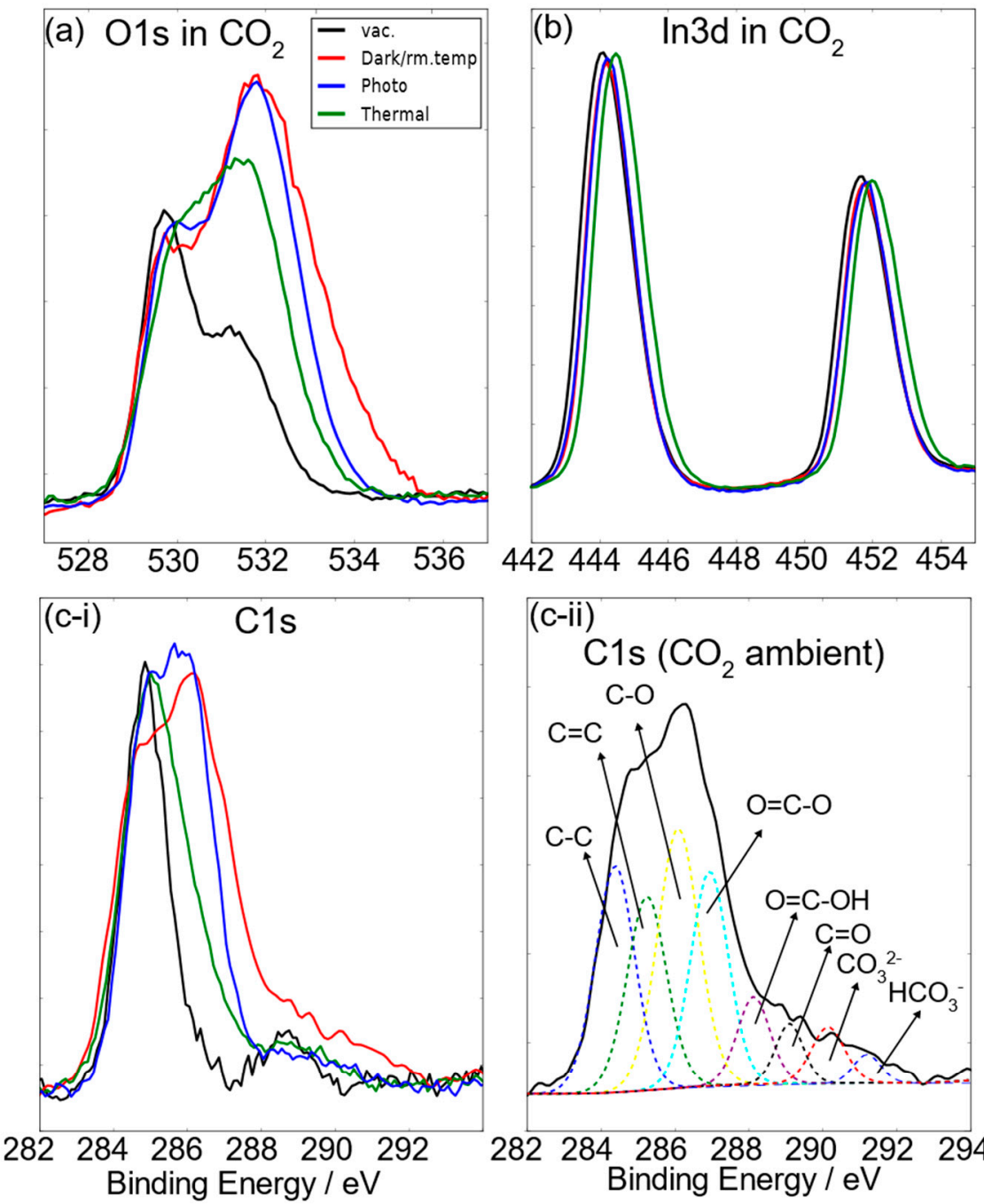

(d)

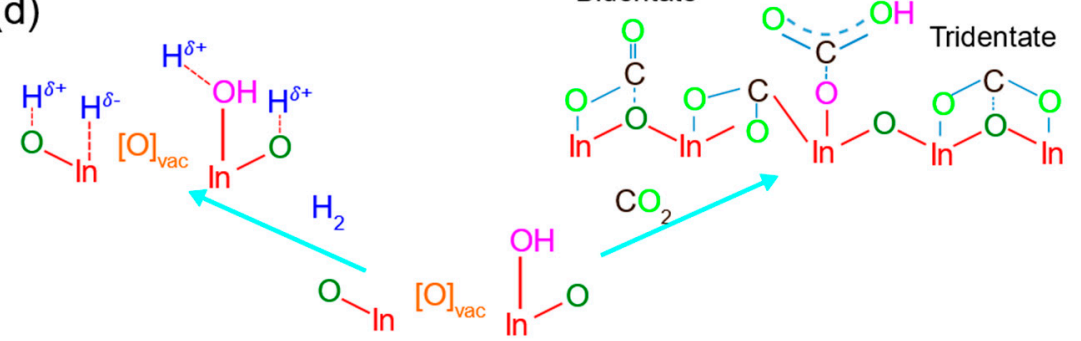

Figure 3. (a-c) The O1s, In3d, and C1s XPS spectra of $\operatorname{In}_{2} \mathrm{O}_{(3-\mathrm{x})}(\mathrm{OH})_{\mathrm{y}}$ nanorods in $\mathrm{CO}_{2}$ under various reactor conditions in comparison with the pristine surface shown in Figure 1. (d) The two adsorption paths for a defective $\operatorname{In}_{2} \mathrm{O}_{(3-\mathrm{x})}(\mathrm{OH})_{y}$ surface for $\mathrm{H}_{2}$ - and $\mathrm{CO}_{2}$-only atmospheres. For bidentate configurations, the adsorption energy was determined [12] to be $-0.70 \mathrm{eV}$; tridentate had $-1.25 \mathrm{eV}$ adsorption energy; and $\mathrm{CO}_{2}$ absorbed on an oxygen vacancy with an adsorption energy of $-0.61 \mathrm{eV}$. 

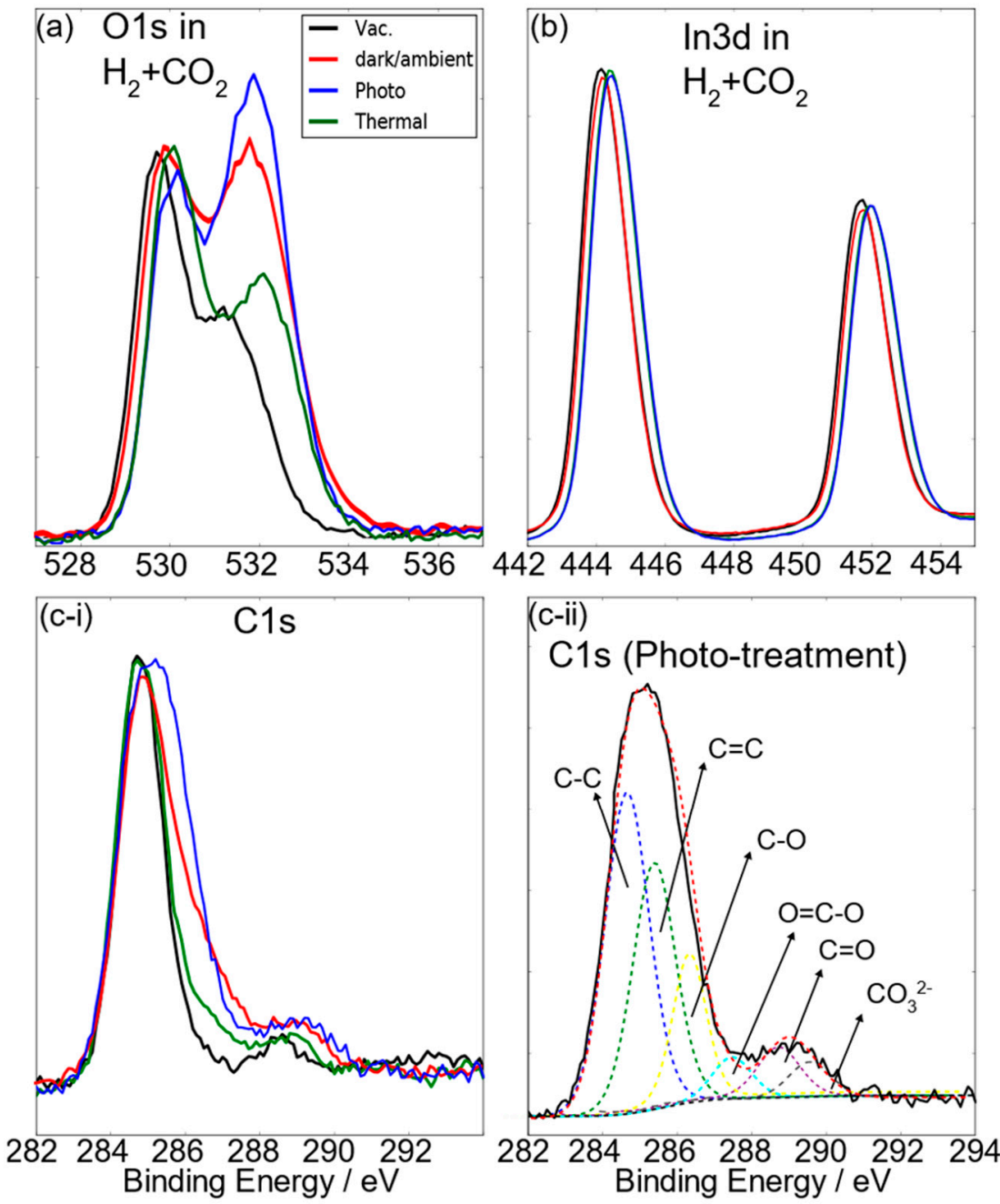

Figure 4. $(\mathbf{a}-\mathbf{c})$ The O1s, In3d, and C1s XPS spectrum of $\operatorname{In}_{2} \mathrm{O}_{(3-\mathrm{x})}(\mathrm{OH})_{\mathrm{y}}$ nanorods in $\mathrm{H}_{2}+\mathrm{CO}_{2}$ under various reactor conditions in comparison with the pristine surface shown in Figure 1. (c-ii) shows the various carbon species in the $\mathrm{C} 1$ s spectrum after $\mathrm{H}_{2}+\mathrm{CO}_{2}$ under photoillumination conditions.

We now turn to in situ Hall measurements to examine the surface reactivity in greater depth (Figure 5). Generally, electrical resistivity (Figure 5a) decreases with photoillumination, with the greatest decrease occurring in vacuum atmosphere with $\mathrm{H}_{2}$, followed by $\mathrm{H}_{2}+\mathrm{CO}_{2}$, and the smallest decrease occurring in vacuum atmosphere for $\mathrm{CO}_{2} \cdot \mathrm{CO}_{2}$ and $\mathrm{CO}_{2}+\mathrm{H}_{2}$ show the smallest photoinduced resistivity decrease of $\sim 10 \%$ and $\sim 13 \%$, respectively. For the associated carrier concentration trends, carrier concentrations also follow the trends of the resistivity plot for vacuum and $\mathrm{CO}_{2}$, however, for $\mathrm{H}_{2}+\mathrm{CO}_{2}$, there is a distinct difference in the temperature dependence slope, with the slope under photoillumination being greater than that of the dark condition. Furthermore, the carrier concentration for $\mathrm{H}_{2}$ dark and photoilluminated conditions are relatively similar in the same order of magnitude, with a steeper temperature dependence under photoillumination than under dark conditions. Generally, carrier mobility decreases under photoillumination, with increased electron-hole pair recombination as a result of carrier concentration increase; hence, there is also a logarithmic linear dependence between mobility and concentration, as shown in Figure $5 c$. $\operatorname{In}_{2} \mathrm{O}_{(3-\mathrm{x})}(\mathrm{OH})_{\mathrm{y}}$ in $\mathrm{CO}_{2}$ atmosphere has generally low carrier concentrations and lower intrinsic carrier mobilities (extrapolated mobilities at very low concentrations) because of higher electron-hole pair recombination rates. Interestingly, the intrinsic carrier mobilities in vacuum are higher than in the $\mathrm{H}_{2}$ or $\mathrm{CO}_{2}$ atmospheres, showing that reactant gas chemisorption induces higher recombination rates. The $\mathrm{H}_{2}+\mathrm{CO}_{2}$ atmosphere mobility concentration trend is, however, very similar to that of the vacuum trend. 

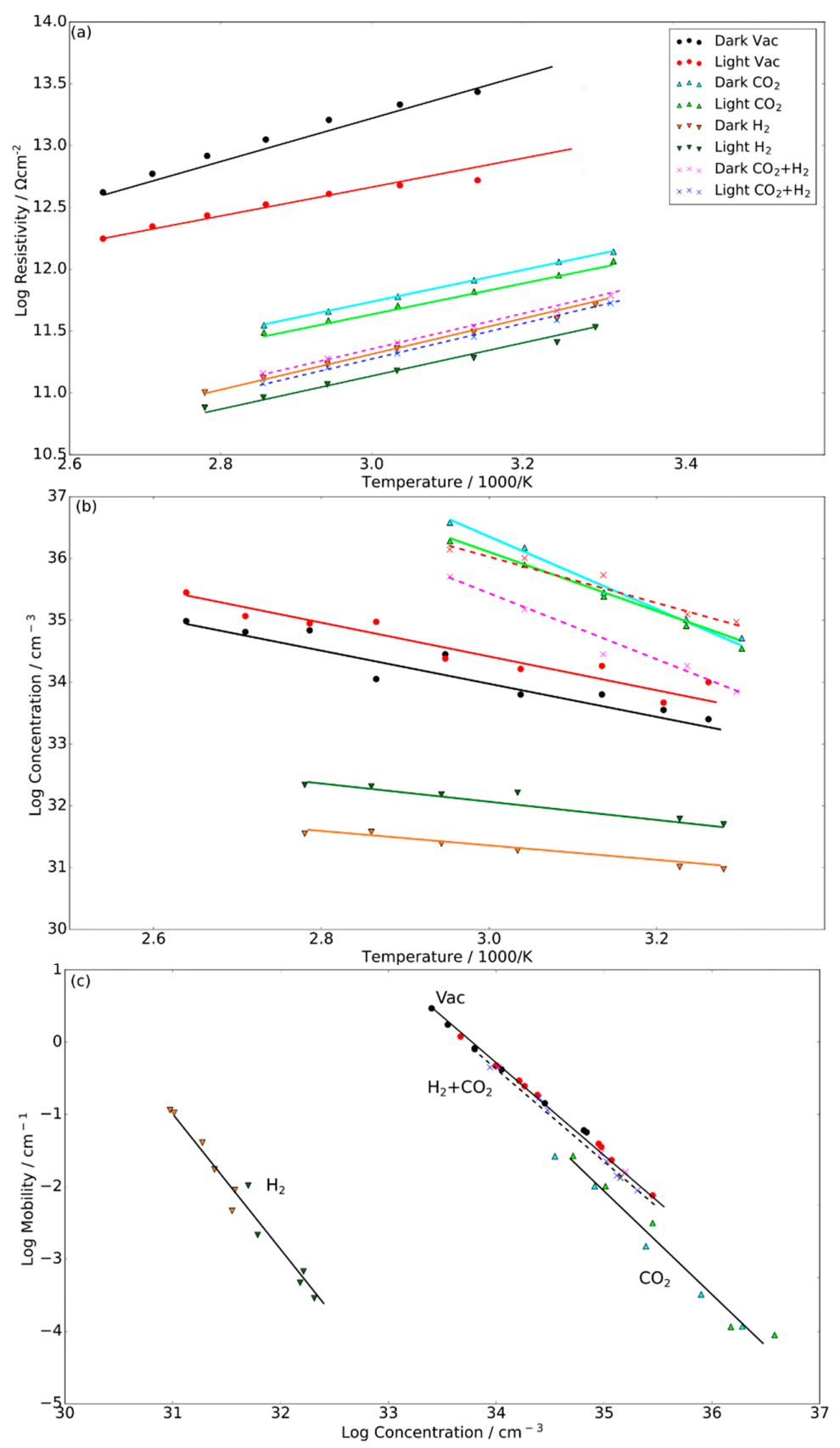

Figure 5. (a) Electrical resistivity and (b) carrier concentration as a function of temperature, with (c) carrier mobility and concentration trends. The results for the vacuum, $\mathrm{H}_{2}, \mathrm{CO}_{2}$, and $\mathrm{H}_{2}+\mathrm{CO}_{2}$ atmospheres are indicated with circle, downside triangle, upside triangle, and cross markers, respectively. Trend lines are shown as a visual guide, with dotted lines representing $\mathrm{CO}_{2}+\mathrm{H}_{2}$ atmospheres.

The trends shown in Hall measurements can be mostly explained by the aforementioned XPS results. A majority homolytic dissociation of $\mathrm{H}_{2}$ injects free electrons through $\frac{1}{2} \mathrm{H}+\mathrm{O}_{\mathrm{L}} \rightarrow \mathrm{OH}^{+}+$ $e^{-}$and $\mathrm{OH}+\frac{1}{2} \mathrm{H}_{2} \rightarrow \mathrm{H}^{+} \mathrm{OH}+e^{-}$, whereas heterolytic dissociation of $\mathrm{H}_{2}$ to form indium hydride generates hole states that can be recombined with any electrons generated from homolytic dissociation. This would explain the sharper increase of carrier concentrations from dark ambient temperature to dark high temperatures, as well as the larger spread of the concentration-mobility trend in comparison to other gas atmospheres. Since the homolytic dissociation of $\mathrm{H}_{2}$ under photo condition is fairly similar to that of the $150{ }^{\circ} \mathrm{C}$ thermal condition, photoillumination and thermal conditions would likely induce greater homolytic dissociation of $\mathrm{H}_{2}$, which can be rationalized in the intersecting trend 
of increasing carrier concentration with increasing temperature under photo and dark conditions. The increase in carrier concentration as a result of $\mathrm{H}_{2}$ dissociation is, however, partly mitigated by the decrease in carrier mobilities, since $\mathrm{H}^{+} \mathrm{OH}$ groups can act as strong electron traps. The trends shown with the $\mathrm{CO}_{2}$-only atmosphere indicate that carbonate adsorption depletes free carrier densities and that surface carbonates act as significant carrier scattering sites that increase recombination rates. Since phototreatment induces less carbonate formation, the depletion of free carrier density is reduced, leading to an increase in free carrier density. Furthermore, carbonate formation decreases with temperature, which can explain the increase in concentration with temperature; however, because carbonates are still seen at high temperatures, the increase in carrier density is more gradual. Under $\mathrm{H}_{2}+\mathrm{CO}_{2}$, the mixture of $\mathrm{H}_{2}$ dissociation and carbonate formation results in a dynamic carrier population that has both the characteristics of $\mathrm{CO}_{2}$ - and $\mathrm{H}_{2}$-only trends. In dark thermal conditions, homolytic dissociation on the $\mathrm{OH}$ group is shown to be more likely than on oxygen lattice sites. As such, the more gradual concentration increase than for $\mathrm{H}_{2}$-only group can be linked to lower dissociation of $\mathrm{H}_{2}$. In photoillumination condition, while the $\mathrm{OH}$ shoulder expansion may indicate either prevalent $\mathrm{H}_{2}$ dissociation or prevalent carbonate absorption, the higher carrier concentration compared to that of dark condition indicates that $\mathrm{H}_{2}$ dissociation is more favored than carbonate absorption. However, the gradual sloping of the temperature dependence in photoillumination may indicate that carbonate absorption is slightly more favored at higher temperatures under photoillumination.

\section{Conclusions}

In conclusion, quasi-operando XPS and in situ Hall measurements with the various reactant atmospheres and reactor parameters have provided a new window into the reaction of gaseous $\mathrm{H}_{2}$, $\mathrm{CO}_{2}$, and $\mathrm{H}_{2}+\mathrm{CO}_{2}$ with nanostructured $\operatorname{In}_{2} \mathrm{O}_{(3-\mathrm{x})}(\mathrm{OH})_{\mathrm{y}}$ under photochemical and thermochemical operating conditions. While changes in the $\mathrm{O} 1 \mathrm{~s}$ and In3d core level ionization potentials clearly depict the dissociative adsorption of $\mathrm{H}_{2}$ on the surface of nanostructured $\operatorname{In}_{2} \mathrm{O}_{(3-\mathrm{x})}(\mathrm{OH})_{y}$, the results clearly distinguish the homolysis from the heterolysis pathway. These results also show the importance of photoillumination and the reason for $\operatorname{In}_{2} \mathrm{O}_{(3-x)}(\mathrm{OH})_{\mathrm{y}}$ as being a high efficacy photocatalyst, which is to induce greater $\mathrm{H}_{2}$ dissociation and carbonate stability than under thermal conditions. The Hall results show the link between the surface compositional changes with electronic activity, with varying temperature and photo-dependences due to the various populations of chemisorbed species. These results show that surface compositions play important roles in the multiple step process of the RWGS, and can be utilized for various photocatalysts and carbon-based nanocomposites [22-24].

\section{Materials and Methods}

Synthesis Procedure: The $\operatorname{In}_{2} \mathrm{O}_{(3-\mathrm{x})}(\mathrm{OH})_{\mathrm{y}}$ nanorod structures discussed in this paper were fabricated through the following steps: $0.397 \mathrm{~g}$ of $\mathrm{InCl}_{3}$ was dissolved in $6 \mathrm{ml}$ ethanol with stirring. A separate mixture of $2.5 \mathrm{~mL} \mathrm{NH} 3 \mathrm{OH}, 7.5 \mathrm{~mL}$ ethanol, and $2 \mathrm{~mL} \mathrm{H}_{2} \mathrm{O}$ was mixed in the $\mathrm{InCl}_{3}$, creating a white suspension. To control for uniform size distributions, the white suspension was immersed in a heated oil bath at $80^{\circ} \mathrm{C}$ with stirring for $10 \mathrm{~min}$. The suspension was then centrifuged, excess solvent was removed, and it was subsequently washed with deionized water. This step was done 3 times before a vacuum drying procedure at $70{ }^{\circ} \mathrm{C}$ for $12 \mathrm{~h}$. The dried powder was then calcined for 12 $\mathrm{h}$ at $250{ }^{\circ} \mathrm{C}$ to form the $\operatorname{In}_{2} \mathrm{O}_{(3-\mathrm{x})}(\mathrm{OH})_{\mathrm{y}}$ phase nanorod structures. The nanorods had an average length of $1800 \mathrm{~nm}, 13 \mathrm{~nm}$ diameter, and Brunauer-Emmett-Teller (BET) derived surface area of $151 \mathrm{~m}^{2} / \mathrm{g}$.

XPS measurements: The reactor-based quasi-operando XPS measurements were performed with the intention of mimicking the reactor sequence in reducing $\mathrm{CO}_{2}$ with $\mathrm{H}_{2}$ with this material system. The powder samples were placed on glass slides and a glass pipette, which were used to roll and drag the powders until a visibly smooth film was obtained. Three samples were prepared for each gas condition $\left(\mathrm{H}_{2}, \mathrm{CO}_{2}\right.$, and $\left.\mathrm{H}_{2}+\mathrm{CO}_{2}\right)$. Each sample was placed in a high vacuum ConFlat flange assembly and sealed with a UV-enhanced transmissive viewport flange using copper gaskets. $\mathrm{H}_{2}$ and $\mathrm{CO}_{2}$ were introduced at $2 \mathrm{~atm}$ pressure after vacuum pumping to $\sim 2 \times 10^{-5}$ mbar. For $\mathrm{H}_{2}+\mathrm{CO}_{2}, \mathrm{H}_{2}$ was 
introduced at $2 \mathrm{~atm}$ pressure, vented to $1 \mathrm{~atm}$ pressure, and $\mathrm{CO}_{2}$ was introduced at 1.6 atm pressure. The reactors were then subjected to phototreatment $\left(40 \mathrm{~W} / \mathrm{cm}^{2}\right.$ intensity white lamp), thermal treatment $\left(150{ }^{\circ} \mathrm{C}\right.$ ), or control condition (no photoillumination and no thermal treatment) for $\sim 12 \mathrm{~h}$. The nanorod samples were then removed from their reactors inside a grade 5 argon-filled glovebox with $\mathrm{O}_{2}$ and $\mathrm{H}_{2} \mathrm{O}$ concentrations of $0.5-0.7 \mathrm{ppm}$ and $0.1-0.3 \mathrm{ppm}$, respectively. They were then attached to the XPS instrument and loaded directly into the instrument. The instrument was an Thermo Scientific ${ }^{\mathrm{TM}}$ ESCALAB $^{\mathrm{TM}}$ XPS system (Thermo Scientific, Waltham, MA, USA).

Hall measurements: The in situ hall measurements were carried out on a modified Nanometrics Hall system, where the sample box was sealed after applying the contact probes on the sample, which had 4 square gold electrodes $2 \mathrm{~mm}$ in width and $500 \mathrm{~nm}$ thickness at the corners of the sample film. The electrodes were set $0.5 \mathrm{~mm}$ apart. After sealing the sample box, a rough vacuum pumping was applied, after which the gas atmospheres were introduced with a 1.3 atmosphere pressure, and a pressure release valve equilibrated the pressure to 1 atmosphere pressure.

Supplementary Materials: The following are available online. Figure S1. XPS deconvolution after $\mathrm{H}_{2}$ immersion. While the Ovac specie remain relatively constant, the OHT group increase by $144 \%$ is significant in $\mathrm{H}_{2}$ dark ambient. $26-28 \%$ of OHB group is lost in photo/ thermal condition. Figure S2. XPS deconvolution after $\mathrm{CO}_{2}$ immersion. Control means dark ambient temperature conditions. For photo condition, there is a significant $\mathrm{C}-\mathrm{O}$ and $\mathrm{O}=\mathrm{C}-\mathrm{O}$ peak whereas in thermal condition $\mathrm{C}-\mathrm{O}$ peak increases. Figure S3. XPS O1s deconvolution after $\mathrm{H}_{2}+$ $\mathrm{CO}_{2}$ immersion. Under dark ambient and photo condition, the $\mathrm{OH}$ shoulder expands to nearly $50 \%$ of the total $\mathrm{O}$ type species. Figure S4. Left figure. $\mathrm{C} 13 \mathrm{CO}_{2}$ isotope testing by GCMS Agilent 5975C with Mass Spectrometry. The $\mathrm{C} 13 \mathrm{O}$ peak is identified at the 1.33 min mark. Right figure, EPR of nanorod powder in quartz capillary tube. To fit the spectrum, the $\mathrm{g}$ factors of 3 spin systems with isotropic states are $2.04 ; 2.116 ; 2.18$ with spin concentration ratios of 0.35:1:0.1 respectively. Figure S5. The UV-Vis spectrum of the $\operatorname{In}_{2} \mathrm{O}_{3-\mathrm{x}}(\mathrm{OH})_{\mathrm{y}}$ powder film, showing the weak absorption tail in the visible which can be associated with band gap deep defects.

Author Contributions: Conceptualization, J.Y.Y.L.; Methodology, J.Y.Y.L.; Software, J.Y.Y.L.; Validation, J.Y.Y.L.; Resources, N.P.K.; Data Curation, J.Y.Y.L.; Writing-Original Draft Preparation, J.Y.Y.L.; Writing-Review \& Editing, J.Y.Y.L., N.P.K.; Visualization, J.Y.Y.L.; Supervision, N.P.K.; Funding Acquisition, N.P.K.

Funding: This research received no external/corporate funding.

Acknowledgments: The authors gratefully acknowledge funding from the Natural Sciences and Engineering Research Council of Canada (NSERC), the Canadian Foundation for Innovation (CFI), and the Ontario Research Fund. The authors also acknowledge the kind assistance of L. He in the preparation of the nanorods, as well as the discussions with Professor G. Ozin and others.

Conflicts of Interest: The authors declare no conflict of interest.

\section{References}

1. Liu, S.; Tang, Z.-R.; Sun, Y.; Colmenares, J.C.; Xu, Y.-J. One-dimension-based spatially ordered architectures for solar energy conversion. Chem. Soc. Rev. 2015, 44, 5053-5075. [CrossRef]

2. Yuan, L.; $\mathrm{Xu}, \mathrm{Y}$.-J. Photocatalytic conversion of $\mathrm{CO}_{2}$ into value-added and renewable fuels. Appl. Surf. Sci. 2015, 342, 154-167. [CrossRef]

3. Ma, Y.; Wang, X.; Jia, Y.; Chen, X.; Han, H.; Li, C. Titanium Dioxide-Based Nanomaterials for Photocatalytic Fuel Generations. Chem. Rev. 2014, 114, 9987-10043. [CrossRef] [PubMed]

4. Hoch, L.B.; Wood, T.E.; O’Brien, P.G.; Liao, K.; Reyes, L.M.; Mims, C.A.; Ozin, G.A. The rational design of a single component photocatalyst for Gas Phase $\mathrm{CO}_{2}$ reduction using both UV and Visible Light. Adv. Sci. 2014, 1, 1400013. [CrossRef] [PubMed]

5. Wang, L.; Ghoussoub, M.; Wang, H.; Shao, Y.; Sun, W.; Tountas, A.A.; Wood, T.E.; Li, H.; Loh, J.Y.Y.; Dong, Y.; et al. Photocatalytic Hydrogenation of Carbon Dioxide with High Selectivity to Methanol at Atmospheric Pressure. Joule 2018, 2, 1369-1381. [CrossRef]

6. Martin, O.; Martín, A.J.; Mondelli, C.; Mitchell, S.; Segawa, T.F.; Hauert, R.; Drouilly, C.; Curulla-Ferré, D.; Pérez-Ramírez, J.; Curulla-Ferré, D.; et al. Indium Oxide as a Superior Catalyst for Methanol Synthesis by $\mathrm{CO}_{2}$ Hydrogenation. Angew. Chem. Int. Ed. 2016, 55, 6261-6265. [CrossRef]

7. Dong, Y.C. Tailoring surface Frustrated Lewis Pairs of $\operatorname{In}_{2} \mathrm{O}_{(3-\mathrm{x})} \mathrm{OHy}$ for gas phase Heterogeneous photocatalytic reduction of $\mathrm{CO}_{2}$ by isomorphous substitution of $\operatorname{In} 3^{+}$with $\mathrm{Bi}^{+}$. Adv. Sci. 2018, 5, 1700732. [CrossRef] 
8. He, L.; Wood, T.E.; Wu, B.; Dong, Y.; Hoch, L.B.; Reyes, L.M.; Wang, D.; Kubel, C.; Qian, C.; Jia, J.; et al. Spatial Separation of charge carriers in $\operatorname{In}_{2} \mathrm{O}_{(3-\mathrm{x})}(\mathrm{OH})$ y Nanocrystal superstructures for enhanced gas-phase photocatalytic activity. ACS Nano 2016, 10, 5578-5586. [CrossRef]

9. Stephan, W.D. Frustrated Lewis Pairs. J. Am. Chem. Soc. 2015, 137, 10018-10032. [CrossRef]

10. Ghuman, K.K.; Hoch, L.B.; Szymanski, P.; Loh, J.Y.Y.; Kherani, N.P.; El-Sayed, M.A.; Ozin, G.A.; Singh, C.V. Photoexcited Surface Frustrated Lewis Pairs for Heterogeneous Photocatalytic $\mathrm{CO}_{2}$ Reduction. J. Am. Chem. Soc. 2016, 138, 1206-1214. [CrossRef]

11. Taifan, W.; Boily, J.-F.; Baltrusaitis, J. Surface chemistry of carbon dioxide revisited. Surf. Sci. Rep. 2016, 71, 595-671. [CrossRef]

12. Ye, J.; Liu, C.-J.; Ge, Q. DFT Study of $\mathrm{CO}_{2}$ Adsorption and Hydrogenation on the $\mathrm{In}_{2} \mathrm{O}_{3}$ Surface. J. Phys. Chem. C 2012, 116, 7817-7825. [CrossRef]

13. Ghuman, K.K.; Hoch, L.B.; Wood, T.E.; Mims, C.; Singh, C.V.; Ozin, G.A. Surface Analogues of Molecular Frustrated Lewis Pairs in Heterogeneous $\mathrm{CO}_{2}$ Hydrogenation Catalysis. ACS Catal. 2016, 6, 5764-5770. [CrossRef]

14. Ghuman, K.K.; Hoch, L.B.; Mims, C.A.; Wood, T.E.; Ozin, G.A.; Singh, C.V. Illuminating $\mathrm{CO}_{2}$ reduction on frustrated Lewis pair surfaces: Investigating the role of surface hydroxides and oxygen vacancies on nanocrystalline $\operatorname{In}_{2} \mathrm{O}_{(3-x)}(\mathrm{OH}) \mathrm{y}$. Phys. Chem. Chem. Phys. 2015, 17, 14623-14635. [CrossRef] [PubMed]

15. Chen, H.-Y.T.; Giordano, L.; Pacchioni, G. From Heterolytic to Homolytic $\mathrm{H}_{2}$ Dissociation on Nanostructured $\mathrm{MgO}$ (001) Films as a Function of the Metal Support. J. Phys. Chem. C 2013, 117, 10623-10629. [CrossRef]

16. Scarano, D.; Bertarione, S.; Cesano, F.; Vitillo, J.G.; Zecchina, A. Plate-like zinc oxide microcrystals: Synthesis and characterization of a material active toward hydrogen adsorption. Catal. Today 2006, 116, 433-438. [CrossRef]

17. García-Melchor, M.; Homolytic, N.L. Products from Heterolytic Paths in $\mathrm{H}_{2}$ Dissociation on Metal Oxides: The Example of $\mathrm{CeO}_{2}$. Phys. Chem. C 2014, 118, 10921-10926. [CrossRef]

18. Yang, J.; Cheng, H.; Martens, W.N.; Frost, R.L. Application of Infrared emission spectrscopy to the thermal transition of indium hydroxide to indium oxide nanocubes. Appl. Spectrosc. 2011, 65, 113-118. [CrossRef]

19. Wagner, M.; Lackner, P.; Seiler, S.; Brunsch, A.; Bliem, R.; Gerhold, S.; Wang, Z.; Osiecki, J.; Schulte, K.; Boatner, L.A.; et al. Resolving the Structure of a Well-Ordered Hydroxyl Overlayer on $\operatorname{In}_{2} \mathrm{O}_{3}(111)$ : Nanomanipulation and Theory. ACS Nano 2017, 11, 11531-11541. [CrossRef]

20. Loh, J.Y.; Kherani, N.P. In Situ Electronic Probing of Photoconductive Trap States for the Catalytic Reduction of $\mathrm{CO}_{2}$ by $\operatorname{In}_{2} \mathrm{O}_{(3-\mathrm{x})}(\mathrm{OH}) \mathrm{y}$ Nanorods. J. Phys. Chem. Lett. 2019, 10, 526-532. [CrossRef]

21. Gan, J.; Lu, X.; Wu, J.; Xie, S.; Zhai, T.; Yu, M.; Zhang, Z.; Mao, Y.; Wang, S.C.I.; Shen, Y.; et al. Oxygen vacancies promoting photoelectrochemical performance of $\mathrm{In}_{2} \mathrm{O}_{3}$ nanocubes. Sci. Rep. 2013, 3, 3. [CrossRef] [PubMed]

22. Khan, M.E.; Cho, M.H. Green synthesis, photocatalytic and photoelectrochemical performance of an $\mathrm{Au}-$ Graphene nanocomposite. RSC Adv. 2015, 5, 26897-26904. [CrossRef]

23. Mohammad, A.; Khan, M.E.; Karim, M.R.; Cho, M.H. Synergistically effective and highly visible light responsive $\mathrm{SnO}_{2}-\mathrm{g}-\mathrm{C}_{3} \mathrm{~N}_{4}$ nanostructures for improved photocatalytic and photoelectrochemical performance. Appl. Surf. Sci. 2019, 495, 143432. [CrossRef]

24. Mohammad, A.; Karim, M.R.; Khan, M.E.; Khan, M.M.; Cho, M.H. Biofilm-Assisted Fabrication of $\mathrm{Ag} @ \mathrm{SnO}_{2}-\mathrm{g}-\mathrm{C}_{3} \mathrm{~N}_{4}$ Nanostructures for Visible Light-Induced Photocatalysis and Photoelectrochemical Performance. J. Phys. Chem. C 2019, 123, 20936-20948. [CrossRef]

Sample Availability: Samples of the compounds are available from the authors. 